\title{
Peer Feedback in Learner-Learner Interaction Practices. Mixed Methods Study on an xMOOC
}

\author{
Josemaria Elizondo-Garcia and Katherina Gallardo \\ Tecnologico de Monterrey, Mexico \\ josemaria.elizondo@tec.mx \\ katherina.gallardo@tec.mx \\ DOI: 10.34190/EJEL.20.18.2.002
}

\begin{abstract}
Although $\mathrm{xMOOCs}$ have shown benefits due to their accessibility to expert knowledge, the quality of their pedagogical proposal remains contested. It has not yet been proven that online education's learner-learner interaction practices in $\mathrm{XMOOCs}$ generate an improvement in the quality of learning and academic achievement. Peer feedback is a practice that can enhance learning in an environment with diverse student profiles and limited instructor participation. The present mixed methods study was devoted to identifying the perceptions of xMOOC participants regarding learner-learner interaction and feedback practices. In the Energy Saving course on MexicoX platform, 1,176 participants answered an initial survey, 486 participants answered a final survey and 14 participants were interviewed after completing the course. Results show that most of the participants are willing to interact with their peers and participate in peer feedback activities. Although, in practice its value for summative assessment is an important factor that may predict involvement. It is found that diversity of expertise level is not an obstacle for participants to interact. Rather, participants consider that they may benefit from diversity by assessing their peer assignments and learning different alternatives and strategies in which a problem can be solved. Further, it is identified that peer assessment activities are more adequate for providing feedback than discussion forums, since the first promotes an environment in which participants can observe the performance of their peers showed in a more complex assignment. The findings of this study allow us to analyse inherent and external factors that configure learner-learner interaction and that affect peer feedback in XMOOCs. It is concluded that more research is needed in order to understand the effect of some factors that may affect peer interaction and peer feedback in xMOOCs and to propose better strategies to improve peer feedback effectiveness.
\end{abstract}

Keywords: feedback, peer feedback, peer review, discussion boards, learner-learner interaction, formative assessment, MOOC

\section{Introduction}

Since their creation and first implementation, massive open online courses (MOOC) have provided an opportunity to gather the knowledge of many people and generate learning. They have afforded open access to content in several disciplines by experts from prestigious universities. That is why MOOCs, since their inception, have been considered promising for distance learning. In recent years, studies have assessed the intrinsic educational value of MOOCs and the advancements they offer in the field of e-learning (Gamage, Fernando and Perera, 2015; Martín, González and García, 2013; Sánchez, 2016).

Although these courses are an innovation in online education, some authors consider that it has not yet been proven that they have a strong enough foundation to represent a jump in pedagogical quality, in terms of generation of learning in comparison with other online training models (Aguaded and Medina-Salguero, 2015, Ramírez-Fernández, 2015). Therefore, it is necessary to know MOOCs' deficiencies, so efforts can be oriented to focus on the dimensions that require the most improvements. Two of these areas is learning assessment and peer interaction.

Their massive scale and the diversity of their participants turn MOOCs into a unique learning environment that deserves to be studied. The diversity of the profiles of MOOCs' participants includes their culture, education level, interests and experience concerning the course's topics and objectives, among other aspects (Chuang and Ho, 2016). This diversity, in consequence, requires being considered to generate appropriate evaluation processes. Further, the students-teachers ratio makes it practically impossible for students to receive from the teacher individual feedback on their performance (Ashton and Davies, 2015). Therefore, two important characteristics that define MOOCs are the diversity of participants' profiles and the inability by instructors to evaluate and guide work individually. 


\section{Literature Review}

\subsection{Learner-learner interaction}

According to Moore (1989), there are three types of interaction required for effective learning: learnercontent, learner-instructor and learner-learner. Learner-learner interaction can be achieved through group activities and peer feedback. Some studies suggest that learner-learner interaction is essential for a better online learning experience and can improve the learners' learning achievements (Gunawardena, LinderVanBerschot, LaPointe and Rao, 2010). Although, this type of interaction is the one that participants prefer the least as it does not fulfil the need for time flexibility required by them (Kurucay and Inan, 2017). In xMOOCs, the two most common peer interaction activities are discussion forums and peer assessment.

\subsection{Feedback in MOOCs}

Richards and Schmidt (2010) define feedback as any information that generates a report on the outcome of a behaviour. In online learning environments, students are interested to know if they will be able to succeed or fail according to the achievement of their educational goals (self-regulated learning) and would like to receive more feedback elements instead of more evaluations (Daradoumis, Bassi, Xhafa and Caballé, 2013). Although instructors can provide better feedback than students, it has been found that students can produce more effective feedback by providing explanations to their peers in terms they understand best and according to their level of understanding (Brookhart, 2017). Furthermore, when students provide appropriate feedback, both the receiving and the giving parties benefit from it. Some studies have found similar and even higher levels of effectiveness in peer feedback than in teacher feedback (Ashton and Davies, 2015, Eksi, 2012; Ruegg, 2015).

Automatic multiple-choice tests to assess knowledge and understanding in the course are commonly used on all platforms. However, there are well-known limitations to this type of mechanisms to measure high-level skills such as analysis, synthesis, and evaluation (Suen, 2014). Although new technologies allow scalable ways to implement discussion forums and review student progress, they remain limited when evaluating and providing feedback for complex tasks such as written work (Admiraal, Huisman and Pilli, 2015; Admiraal, Huisman and Van de Ven, 2014; Piech et al., 2013). Further, the limited capability of the teacher to evaluate individual performance has led to an increased interest in developing alternative automatic evaluation practices and in researching them in order to be more valid and reliable, as well as to improve peer evaluation practices (Daradoumis, Bassi, Xhafa and Caballé, 2013; Reilly, Stafford, Williams and Corliss, 2014; Spector, 2014).

\subsection{Peer feedback in MOOCs}

Peer evaluation has been used extensively in MOOCs due to two advantages that no other mechanism has: it allows the evaluation of large groups because the evaluation and feedback are carried out by other participants instead of the teacher. Further, it allows the evaluation of products that could not be evaluated automatically (Kulkarni et al., 2013). Yurdabakan (2016) points out that this technique has been used for decades, which highlights some benefits noted in the literature prior to the emergence of MOOCs: peer evaluation emphasizes skills, encourages participation, increases the focus of attention towards learning, provides feedback to students, increases attendance and teaches responsibility, develops critical thinking, increases student learning and encourages collaborative learning.

Peer evaluation also helps students see the work from an advisor's perspective. Evaluating the work of their peers exposes students to solutions, strategies, and points of view that they would not see otherwise (Kulkarni et al., 2013). Najafi, Rolheiser, Harrison and Haklev (2015) point out that peer review is an opportunity for participants to reflect on the knowledge acquired and to apply it. The positive effect of peer feedback increases as the feedback is based on the meaning of the task on not on its surface characteristics. Thus, peer review is more effective when based on higher order writing elements, rather than relying on matters of lower order (Comer, Clark and Canelas, 2014; Cho and Cho, 2011). This effectiveness increases when incorporating rubrics with precise terminology that can adequately guide the participants (Kulkarni et al., 2013, Ashton and Davies, 2015).

Although students benefit both from giving and receiving assessments and feedback, they hold divided opinions regarding peer review. While some firmly believe that this benefits their learning, others do not 
consider it useful and prefer to not participate in it (Meek, Blakemore and Marks, 2017. That is, while some believe that it improves their learning, increases their motivation and leads them to develop critical thinking, other students consider it difficult, uncomfortable and time-consuming (Mulder, Pearce and Baik, 2014; Yurdabakan, 2016). Bali (2014) reported less participation in peer review activities when these are nonmandatory.

Moreover, many students consider that their classmates do not possess the necessary abilities to evaluate their work nor provide adequate feedback (Johnston, 2015). Meek, Blakemore and Marks (2017) state that it is difficult to say that the participants of a MOOC have peers since some of them are not familiar with the same knowledge areas or even share the same language. The authors also point out that it is not realistic to expect every student to carry out peer evaluation when some of them are not actively engaged with the course or have another level of commitment in relation to it.

\subsection{Discussion forums}

As a means of social learning, MOOCs rely on interaction with others, as is the case in discussion forums, in which participants can provide valuable feedback for the student and for other classmates who read them. Lee and Rofe (2016) designed an evaluation mechanism that would enhance peer learning in MOOCs, so they changed the dynamics of peer evaluation in a way that privileged feedback. The students were asked to present in the discussion forums the assignments that would be evaluated by peers and to provide feedback. In this way, students perceived areas of opportunity on which they could improve their work and thus submit a better product for evaluation. Also, these forums became a space where they could find many examples of how others performed the task. In this way, using discussion forums, the socialization of peer learning was leveraged. Peer review can be a good mechanism to encourage interaction among peers in cases that generate discussion to improve performance (Johnston, 2015).

Discussion forums in $\mathrm{xMOOCS}$ are affected by MOOC characteristics, as well as peer assessment practices. It has been found that MOOC's participants consider that dialog between peers is not fluid and does not facilitate a speedy exchange of ideas (Liu, Kang and McKelroy, 2015). As in other online environments, it has been found that participants have different roles while participating in discussion forums. Further, Wang. et. al (2015) found that participants with the role of observers in discussion forums in MOOCs learn even when they do not type comments.

\subsection{Factors that affect peer interaction}

Some studies on peer interaction in XMOOCs focus on factors and strategies used for improving engagement and involvement. They suggest that by incorporating some of these elements peer interaction and peer feedback may be improved. Some elements are described below:

Social involvement. It is a factor that can be decisive in the achievement of the MOOC participants' goals. A study by Kizilcec and Schneider (2015) showed that learners with the intention of taking the course with colleagues or friends were more likely to complete the course and obtain a certificate. These learners were more involved with the course materials (watch videos and perform the required tasks) than those who did not sign up with someone else.

Level of expertise. Mackness, Mak and Williams (2010) pointed out that the difference in the levels of expertise of the participants in a MOOC can hinder their openness, connection and interactivity. In their study it was identified that $8 \%$ of the participants who decided to stop participating in the forums gave as a reason the difference in the levels of expertise among the novices and the participants familiar with the concepts and technologies.

Anonymity. Peer review can be a good mechanism to encourage interaction among peers in cases that generate discussion to improve performance. This also considers that students will be more likely to accept feedback if their peers are like them in terms of knowledge of the subject and if the students know the name of their reviewers, even if they do not know each other outside the course (Johnston, 2015; Lu and Bol, 2007).

Training. Training videos are an effective alternative to promote more participation and better engagement in MOOCs (Ashton and Davies, 2015; Luo, Robinson and Park, 2014). Other types of trainings prepare participants 
to offer accurate scores by asking them to grade an assignment evaluated previously by an instructor (Ashton and Davies, 2015; Kulkarni et al., 2013).

Scoring the feedback. In a study, students who received a grade on their feedback given to a peer offered more extensive and detailed feedback (Neubaum, Wichmann, Eimler and Krämer, 2014). By increasing the complexity and degree of responsibility of the participant, peer evaluation is one of the most challenging and promising types of evaluation instructors can include in a MOOC.

\subsection{Approach}

Although the advantages and benefits of the learner-learner interaction are recognized in virtual learning environments, there is not enough evidence from research to recognize these benefits on xMOOCs. Moreover, some suggestions and proposals have been made to improve peer interaction, but these do not usually consider the participants' perceptions. Thus, there is a need to delve deeper into the experiences of these participants to identify the most appropriate conditions for XMOOCs in which participants could enhance their learning through interaction with their peers.

The learner-learner interaction processes proposed by xMOOCs are very limited by their learning model. Their instructional model tends to place greater emphasis on the learner-content interaction, ignoring the kind of learning that can occur in the learner-learner relationship and collaborative work. It is necessary to know more about the experiences of the participants to identify what are the favourable conditions in which they can improve their learning from the interaction with their peers.

Feedback has been considered an educational process with important benefits in learning, which can have a positive impact on its effectiveness. In addition, the benefits for participants of engaging in peer interaction and feedback activities in XMOOC have not been sufficiently explored. Based on this approach, the following research question was established: What perceptions do participants in xMOOCs have concerning the factors that affect peer interaction and peer feedback?

\section{Method}

\subsection{Context}

The context in which the research was carried out was the first implementation of an xMOOC called Energy Saving, using the MexicoX platform. The theme of energy saving is incorporated into the current need for sustainable development and care of resources. Thus, it attracts a diversity of learners interested in knowing new and alternative measures to reduce and make more efficient the energy consumption in their home, in industry, in transport and, even, from within infrastructure.

In the first implementation of the Energy Saving course, 4,402 registered participants had enrolled. These are all those who have an account in the MexicoX platform and chose the Energy Saving course to access and receive information by e-mail about it. Of these, 1,459 completed at least one course activity, that is, they received a grade in at least one course activity. The duration of the course was six weeks and every week corresponded to a different theme.

The Energy Saving course included both typical peer interaction practices in XMOOCs, discussion forums and a peer review activity. A different discussion forum was attended by participants every week of the course. Every discussion forum started with three activating questions or sentences that participants would use to share their opinions and impressions. They were not explicitly asked to give feedback but to look over their peers' comments and contribute to the discussion.

Further, the course included a peer review activity. During the third week students were asked to elaborate a three-action plan to save energy at home, in which they should include energy measurements and economic savings. Then, during the fifth week they shared a link with their plan. Participants had one week to review their peers' assignment. They used a checklist to indicate whether required assignment elements were included or not. It was ensured that each assignment would be reviewed by five peers and every participant would review five assignments. Only those participants who reviewed their peers' assignments received a grade on their assignment. 


\subsection{Design}

To answer these research questions, a Mixed Methods design was chosen, with dominant and sequential status. Quantitative research was carried out first, followed by qualitative research. The dominant status focused on the qualitative part (Johnson and Onwuegbuzie, 2004). Given the mixed nature of this study, when defining the instruments, it was sought that the quantitative approach would allow knowing the general perceptions of the participants. On the other hand, the qualitative approach would allow capturing in detail the experience and beliefs that the MOOC's participants have about the formative evaluation processes presented in them.

Within this Mixed Methods study a descriptive method was considered for the quantitative research. Regarding the qualitative part of the study, a phenomenological approach was chosen (Tójar, 2006) to conduct the study. A phenomenological approach focuses on understanding the meaning that events have for people as a centre of study. The main objective is the attempt to understand the object of the experience of the phenomenon (Wilding and Whiteford, 2005), which in this case is the learner-learner interaction in a MOOC.

\subsection{Participants}

Most of the course participants were Mexican (97\%). The rest of the participants reside in Spanish-speaking countries such as Colombia, Ecuador and Argentina. 35\% of the participants had a high school degree and 36\% had an undergraduate degree, as the highest level of studies; $11 \%$ had a technical degree, and $11 \%$ had a master's degree. Regarding the discipline of studies of their technical career, undergraduate or graduate, $39 \%$ said that Engineering or Computer Science was their area of knowledge, while $15 \%$ indicated Business Administration and $8 \%$ indicated Natural Sciences. As their main occupation, $35 \%$ of the participants indicated that they were an undergraduate student, and $35.8 \%$ indicated that they were full-time employees. Additionally, $52 \%$ indicated that it was the first time they participated in a MOOC.

From the 486 participants who answered the final survey, 272 participants agreed to be contacted by e-mail to share their experience in the course. All these participants were contacted to request an interview. Interviews were conducted with those participants who replied the e-mail and agreed to have a meeting by video conference. In total, 14 were conducted.

\subsection{Instruments}

For the quantitative research, surveys at the beginning and the end of the course were conducted. The survey at the beginning of the course included five multiple-choice questions related to the dispositions and beliefs of the participants for peer interaction and feedback (see Appendix 1). The survey at the end of the course included eight questions, six of multiple choice and two open-ended, related to their participation and satisfaction in activities of interaction and feedback between peers in the Energy Saving course (see Appendix 2).

For the qualitative research, a semi-structured interview and an instrument for participant observation were designed. The semi-structured interview consisted of 15 questions designed with the intention of knowing the participants' experience in the learner-learner interaction activities and the automatic and peer feedback activities (see Appendix 3). In addition, a participant observation guide was designed to keep track of the interactions in the discussion forums of the course and thus be able to demonstrate the experiences, relationships and constructions of knowledge that arose among the participants of the course. The observation in the discussion forums was made considering the characteristics of feedback presented by Shute (2008) and Nelson and Schunn (2009).

\subsection{Procedure}

The initial survey was conducted at the beginning of the course. It was one of the first activities that the participants carried out for the course, alongside the general instructions and the agenda of the course. The final survey was added in the last lesson of the course, so it was answered by the participants after concluding all the learning activities.

In the final survey of the course, a final question was included in which the participants indicated if they were willing to be contacted via e-mail to comment on their experience throughout the course. In this way, by email, all participants were requested to attend a virtual interview with an approximate duration of 30 minutes. 
Once their acceptance and confirmation were received, they were given a link to a virtual room to be interviewed at a time convenient to the participants.

\subsection{Data analysis}

First, a descriptive analysis of the quantitative data obtained from the initial and final surveys was carried out. This data also guided the orientation of the interviews conducted later. After observing the discussion forums and transcripts of the interviews, the analysis of the data obtained through the interviews and the discussion forums continued. The names of the participants interviewed were coded to protect their identity.

For the process of data analysis, the steps indicated by Apps (1991, cited by Tójar, 2006) for phenomenological studies were followed. This author follows the epistemological proposal of Husserl (1965), who considered the phenomenological reduction, and the imaginative variation to capture the essence of the phenomenon. The directions of Merriam and Tisdell (2015) to build and name the categories (or topics) were also considered.

\section{Results}

With the quantitative study, the dispositions and general beliefs of the participants were analysed, along with information on their participation in the interaction activities. For the qualitative study 14 interviews were conducted. The following categories emerged, which refer to factors both inherent to and external to the participants that configure the learner-learner interaction that have an impact on the feedback between peers in MOOCs: 1) Dispositions and interest to interact, 2) Instructional mediators, 3) Participants' expertise, and 4) Utility of peer feedback.

The quantitative and qualitative results that describe each category of analysis are presented below.

\subsection{Peer interaction}

\subsubsection{Interaction interests}

Below are some results obtained from the exit survey. Concerning participation rate in discussion forums, $44 \%$ of the participants indicated that they participated in all or some of the units. Further, $70 \%$ of the participants indicated that they agreed or strongly agreed with perceiving an improvement in their knowledge on the course's subject by participating actively in the discussion forums.

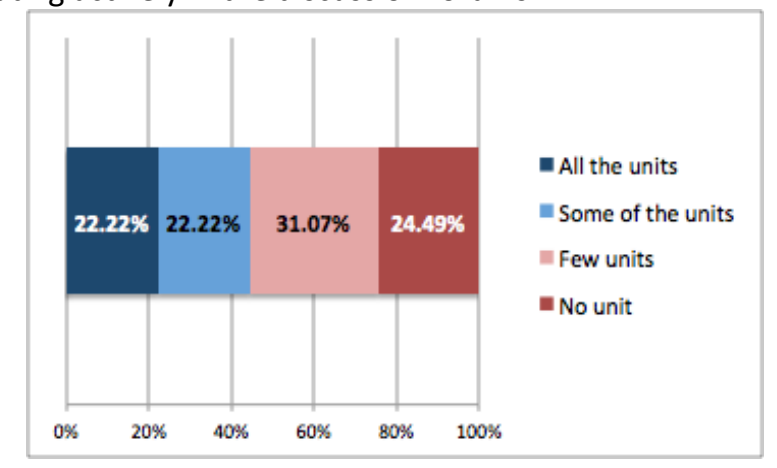

Figure 1: Participation in the discussion forums

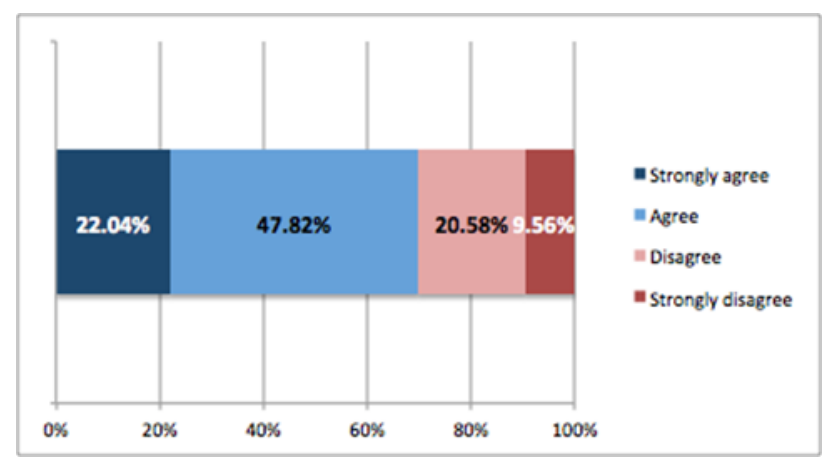

Figure 2: I improved my knowledge on the course's subject by participating in the discussion forums 
Regarding discussion forums, $64 \%$ of the participants indicated that they agreed or strongly agreed that they found the answers to their questions about the course's subject by participating in the discussion forums. In addition, $28 \%$ indicated that they helped other participants with their questions through the discussion forums. However, the comments in the final survey indicate that some of the participants did not find answers to their questions in the discussion forums and that they could hardly establish a conversation, that is, an exchange of ideas.

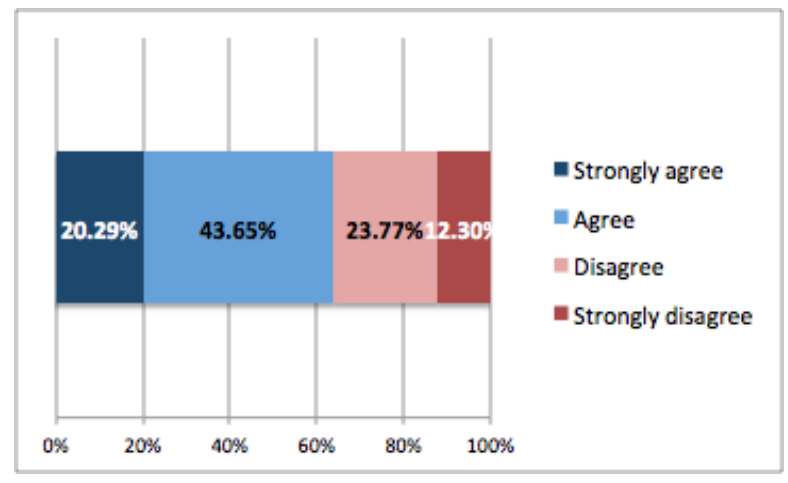

Figure 3: I solved my questions on the course's subject in the discussion forums

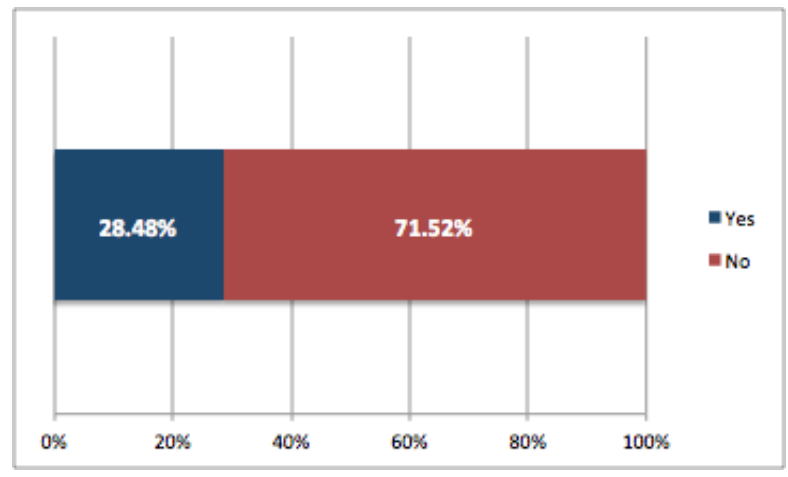

Figure 4: I solved the questions of other participants in the discussion forums

Based on the qualitative results, it was possible to study the interaction interests of the participants. It was identified that participants develop different roles and types of activities during interaction (analyse, reflect, share, etc.) The diversity of profiles presented in the sample of this study also reflects the diversity of purposes and roles during an interaction. While some participants access the discussion forums only as observers, there are others who prefer more active participation.

Those participants that consider their selves as novices opt for only to read comments rather than to bring answers to peers. A participant [P11] indicated: "I asked many questions, because it was a new theme for me. I opted to use It to solve my doubts." So, roles of participation in discussion forums are determined for participants' self-perception of expertise.

\subsubsection{Dispositions to interact}

Most of the participants (92\%) indicated that they agreed or strongly agreed that they would be willing to dedicate at least one hour a week to provide feedback on the work of other participants. Also, $96 \%$ of the participants indicated that they agreed or strongly agreed that they thought providing feedback on the work of others helped them to improve their knowledge on the study subject. 


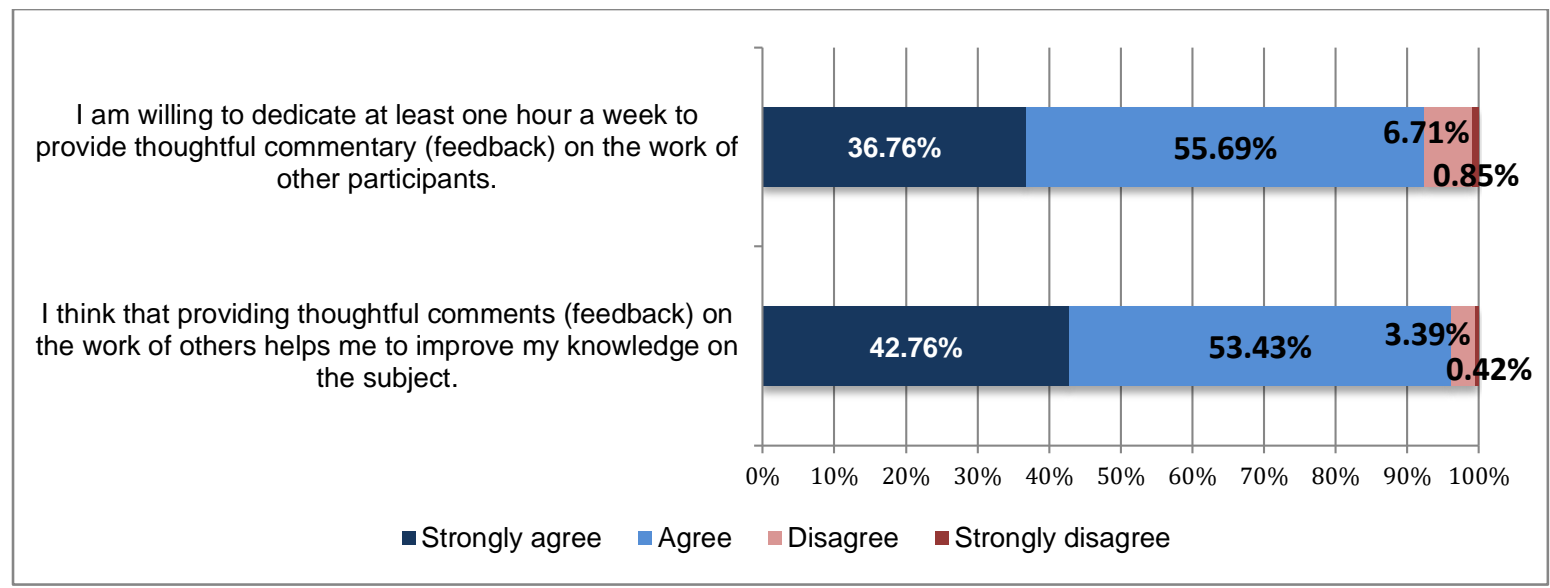

Figure 5: Participants' dispositions and beliefs on peer feedback

Time disposition and perception of feedback efficacy are not factors that hinder their participation in learner-learner interaction and feedback activities. It is important to point out that, even when most of the participants that concluded the course showed disposition to participate in discussion forums and peer review activities, some participants could prescind from participation in these activities and still obtain the course certification. From 733 participants who obtained an approving grade, 178 participants obtained a grade different than zero (0). Those participants submitted their assignment and assessed at least three other assignments.

\subsection{Instructional mediators}

One instructional mediator that was used in the course to improve the feedback practice was to include a video explaining how to evaluate the work of other participants, in preparation for peer review activity. Several participants, $82 \%$, indicated that they watched this video. Through the interviews, other instructional mediators could be found in these courses, carried out through technological elements.

Regarding the clarity of the assignment instructions, there were some participants who considered that in the practice of peer evaluation some instructions were a bit ambiguous, so they were limited as to how to provide better feedback. Moreover, participants needed to use another service as Slide Share o Google Drive to upload the assignment and then copy the link in the MOOC interface, this condition was an obstacle for some participants that had not use this type of service.

In the interviews, participants suggested some improvements to facilitate participation in discussion forums. Participant [P8] said: "I think there could be a notification that can take you to an e-mail and let you know when someone replied to your comment. Otherwise, you need to keep checking the website." In addition, participant [P14] indicated: "I think the forums should include a point, which would be 'give your opinion on the subject or whatever, and do some research on the subject,' and that would give you the opportunity to contribute something else".

\subsection{Participants' expertise}

When asked about their willingness to participate with others according to their level of experience, $91 \%$ of the participants agreed or strongly agreed that they would be willing to participate in discussion groups with participants with the same level of experience as theirs on the course's subject. In addition, $96 \%$ of the participants agreed or strongly agreed to be willing to share knowledge or experience with participants who have less experience on the subject. Of these participants, $24 \%$ had previously reviewed written works by other participants in MOOC courses. 


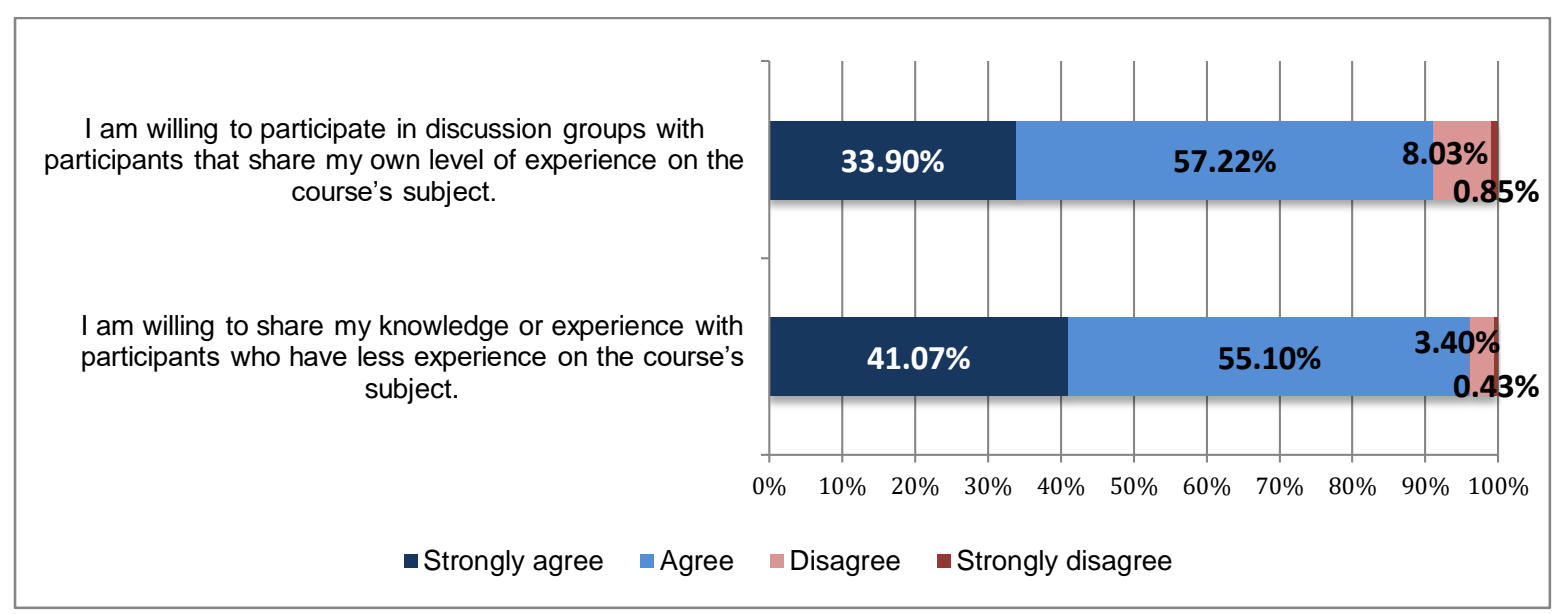

Figure 6: Participants' dispositions on peer interaction according to the level of expertise

Although the participants indicated a willingness to collaborate with participants with different levels of mastery on the subject, it is important to indicate that they acknowledged the diversity in the levels of knowledge and mastery on the course subject and the degrees of responsibility of the participants. This was expressed by [P11] by declaring "The amount of knowledge that people had in the topics discussed in the forums was very noticeable. And in the practice part, I think some took it very seriously and some did not. There was a noticeable difference in the quality of the work of our classmates."

The expertise of the participants not only makes them more capable of providing more informed and precise comments. The participants also take advantage of their previous experiences to generate strategies that help them to advance successfully in the course. Some interaction strategies carried out in the course were started by initiative of the participants, who reported having previously acquired this type of experience. The participant [P4] commented: "What I did was to look up my partner's e-mail in the welcome forum and I shared the link I had told him about in the forum ... During my online master's program, that was something we were asked to do."

\subsection{Utility of feedback}

By asking the participants if they had been provided feedback in the discussion forums, participant [P10] mentioned: "The forums had very simple comments such as 'I agree with the subject and I think it's a good strategy for saving energy' and there were people who answered like that, obviously that is not a contribution". In addition, participant [P2] noted: "Yes, there is some feedback, but more like 'I agree with what you're saying.' Nobody really refuted anything, nobody told me: 'Hey, but look, there's also this..."' Through observation in the discussion forums, comments such as: "You are correct" and "Good point" could be found.

On the other hand, participants found benefits when reviewing the work to provide feedback. Participant [P9] said: "A lot of those comments from your classmates are very valuable, you have a point of view according to the way you are. Because other classmates think differently. They have a different experience, so they can exchange different ways of solving a problem, of arriving at different solutions." In addition, participant [P6] commented: "I think you can see other points of view, that is important, what each person is focused on, the strategies they implement and above all the way in which they work. That gives you a lot, how everyone thinks differently and presents their work in a different way. It gives you knowledge in terms of points of view, how everyone analyses the information and how the information is presented. Not all of us think of water, electricity and gasoline, for example; there are some people who thought of additional things. For example, solar water heaters, things that had not occurred to me, and maybe they are good options for energy saving, which was the main theme of the course".

The diversity of profiles of the participants allows them to get to know different perspectives or approaches to contextualize, understand and solve a problem. This represents an opportunity to acquire new knowledge at different levels. Diversity is considered by the participants themselves as an advantage of these courses because they have multiple experiences that contribute to their own understanding. Participant [P12] said: "The advantage is that they are not people from your own area. My way of seeing the problem is different. It helps you to be more global. For example, if you work in a company that distributes in Mexico, you can get to know different ways of how the processes of production, marketing, etc. are carried out in other places." Also, when asking participant [P9] what kind of advantages he finds when interacting with other participants, he commented: "Because people from different states and countries participate. I can get different points of view. There is a cultural exchange that is important to me." 
When asked about the separation by groups of collaboration according to the characteristics of the participants, they did not consider it convenient, as that would eliminate these benefits provided by diversity. When asking if it would be convenient to make subgroups in the forums to improve the interaction, the participant [P3] commented: "It would be difficult to assign them because maybe I could tell you, I know of sustainability but maybe I'm not very immersed in the issue of energy saving. And maybe some would see it as a kind of discrimination."

\section{Discussion}

The results of this study support the discussion regarding the convenience of integrating working groups in MOOC courses and the criteria for integrating these groups. This is a recent debate, for which there are still few studies devoted to finding better proposals (Kizilcec, 2013). In this regard, it is worth mentioning that participants disagree on separating according to their level of expertise. Participants consider that by integrating working groups in MOOC the opportunity to know the experiences of other participants is reduced. In the present study, it is evident that the participants consider diversity an enriching learning opportunity, as it allows them to know different ways in which the same problem can be contextualized, understood and solved.

Furthermore, Mackness, Mak y Williams (2010) had reported that differences in expertise level of participants may hinder their openness, connection and interactivity. In contrast, results of the present study show that participants are willing to interact and provide feedback to participants with different levels of expertise. In the present study we found that limitations to interact and provide feedback are not due the differences in participants levels of expertise. Rather, some conditions that limit these processes refer to participants' perception of their capacity to evaluate and to the relevance of the activities for obtaining knowledge that may be applied in their professional activities. These results are consistent with Meek, Blakemore y Marks (2016) results, which identify that participants have divided opinions about the benefits of feedback. While some believe that it improves their learning and increases their motivation, other students find it difficult, uncomfortable and time-consuming.

In the present study we found that participants identify other benefits of peer feedback in xMOOCs with respect to other virtual environments. Bali (2014) had identified that participants describe examples of their own country of origin in the discussion forums. Further, we found that the participants associate the usefulness of the feedback to the diversity of participants, since they receive different solutions to the problems presented. In this course, it was also identified that by providing feedback in peer evaluation practice, participants see products from their peers and recognize the characteristics of good practices. These results coincide with Kulkarni et al. (2013) who pointed out that feedback helps the student see the work from an advisory perspective. They also coincide with what Meek, Blakemore and Marks (2016) marked out, that evaluating the work of their peers exposes students to solutions, strategies and points of view that they would not otherwise see.

Results of the current work agree with those from Bali (2014) who reported that participation in peer review activities was affected by the non-mandatory character of these activities in the MOOC. It is shown that summative value of peer interaction and peer review activities is associated with the level of participation on these activities. This occurs even when most of participants indicate high disposition to interact and review. Further, these results agree with previous findings about the importance of training videos as an effective alternative to promote more participation and better engagement in MOOCs (Ashton and Davies, 2015; Luo, Robinson and Park, 2014).

Regarding peer feedback in discussion forums, the students criticized that some of the received feedback only stayed in the agreement or disagreement of what was proposed. This type of feedback was considered less effective by participants. These results agree with what Cho and Cho (2016) pointed out, the positive effect of feedback on performance increases as it is based on the meaning and not on surface characteristics of homework.

\section{Conclusions}

Results of the present study permit a better understanding of factors that affect learner-learner interaction in MOOCs. In order to promote peer interaction and peer feedback in MOOCs it is important to consider this learning environment' conditions, thus to propose ideas that may counter its disadvantages and leverage its benefits. For instance, while massivity and diversity in online courses may be conceived as impediments to an appropriate interaction that promotes learning, benefits in participants' learning can be found. Moreover, some suggestions from MOOC participants should be considered to improve their interaction in this learning environment.

These results allow to understand the importance of performance observation to improve the quality of peer feedback. It is known that feedback provided from one student to another is based on the observation of their performance. Peer review activities have the virtue of presenting to the reviewer a complete elaborated product that show student progress. That facilitates the opportunity to evaluate participant competences. Moreover, in discussion 


\section{The Electronic Journal of e-Learning Volume 18 Issue 22020}

forum activities participants express mainly opinions, rather than a more complex task. That hinder the opportunity to evaluate participant competences and skills.

Although xMOOCs participants have higher levels of disposition to interact, there are some conditions that hinder these opportunities. It is relevant to point out that, in online education, the practice of peer evaluation is rarely framed within a learner-learner interaction space that could foster participants knowing each other, their cooperation and collaboration for learning (Avery, 2016). Therefore, it is convenient to rethink the feedback processes within a formative process of social learning in online education that could facilitate feedback processes.

\subsection{Future research}

The implementation of MOOCs is usually based on models of direct instruction and cognitive-behavioural theories. Within the framework of these theories, MOOC designers create learner-learner interaction dynamics. However, interactions that arose from these dynamics could be designed and described based on other theories that are related with social construction of knowledge. Additionally, the technological functions of the platform should be supported by instructional considerations that allow the reformulation of these dynamics.

Future studies are suggested in order to verify which factors of socialization practices among peers are linked to better performance of the participants and an improvement in the quality of feedback comments. In addition, studies devoted to measuring the effectiveness of working groups in xMOOCs for collaborative learning and their relationship with the quality of feedback and learning achievements are encouraged.

\section{Acknowledgements}

This research has been done with the support of the Project 266632 "Laboratorio Binacional para la Gestión Inteligente de la Sustentabilidad Energética y la Formación Tecnológica" [Binational Laboratory for the Intelligent Management of the Energy Sustainability and the Technological Formation], with funds from the energy sustainability fund CONACYT-SENER (Agreement: S0019-2014-01).

\section{References}

Admiraal, W., Huisman, B. and Pilli, O., 2015. Assessment in massive open online courses. The Electronic Journal of e-Learning (EJEL), 13(4), pp.207-216.

Admiraal, W., Huisman, B. and Van de Ven, M., 2014. Self- and peer assessment in Massive Open Online Courses. International Journal of Higher Education, 3(3), pp.119-128.

Aguaded, I. and Medina-Salguero, R., 2015. Criterios de calidad para la valoración y gestión de MOOC/Quality criteria for the valuation and management of MOOC. Revista Iberoamericana de Educación a Distancia, 18(2), pp.119-143.

Ashton, S. and Davies, R. S., 2015. Using scaffolded rubrics to improve peer assessment in a MOOC writing course. Distance Education, 36(3), pp.312-334.

Avery, T., 2016. Discussing discussions: Online instructor best practices. 8th International Conference on Education and New Learning Technologies (EDULEARN), Spain, pp. 5594-5604. [online] Available at <https://tspace.library.utoronto.ca/bitstream/1807/74701/3/Discussing\%20Discussions.pdf> [Accessed 25 April 2018]

Bali, M., 2014. MOOC pedagogy: Gleaning good practice from existing MOOCs. Journal of Online Learning and Teaching, 10(1), pp.44-56.

Brookhart, S. M., 2017 (2nd Ed.). How to give effective feedback to your students. VA, USA: ASCD.

Cho, Y. H. and Cho, K., 2011. Peer Reviewers Learn from Giving Comments. Instructional Science, 39(5), pp.629-643.

Chuang, I. and Ho, A. D., 2016. HarvardX and MITx: Four Years of Open Online Courses--Fall 2012-Summer 2016. [pdf] Available at $<$ http://dx.doi.org/10.2139/ssrn.2889436> [Accessed 24 April 2018]

Comer, D. K., Clark, C. R. and Canelas, D. A., 2014. Writing to learn and learning to write across the disciplines: Peer-to-peer writing in introductory-level MOOCs. The International Review of Research in Open and Distributed Learning, 15(5), pp.26-82.

Daradoumis, T., Bassi, R., Xhafa, F. and Caballé, S., 2013. A review on massive e-learning (MOOC) design, delivery and assessment. Proceedings of the P2P, Parallel, Grid, Cloud and Internet Computing (3PGCIC), 2013 Eighth International Conference, pp. 208213. IEEE. [online] Available at

<https://www.researchgate.net/profile/Santi_Caballe/publication/261158931_A_Review_on_Massive_ELearning_MOOC_Design_Delivery_and_Assessment/links/O0b7d53967eb12e732000000/A-Review-on-Massive-E-LearningMOOC-Design-Delivery-and-Assessment.pdf> [Accessed 25 April 2018]

Eksi, G. Y., 2012. Peer review versus teacher feedback in process writing: how effective?. International Journal of Applied Educational Studies, 13(1), pp.33-48.

Gamage, D., Fernando, S., and Perera, I., 2015. Quality of MOOCs: A review of literature on effectiveness and quality aspects. Proceedings of the Ubi-Media Computing (UMEDIA), 8th International Conference, pp. 224-229. IEEE. [online] Available at $<$ https://www.researchgate.net/profile/Indika_Perera/publication/281241971_Quality_of_MOOCs_A_review_of_literature_ on_effectiveness_and_quality_aspects/links/55e92d2808aeb65162647486.pdf > [Accessed 25 April 2018]

Gunawardena, C. N., Linder-VanBerschot, J. A., LaPointe, D. K. and Rao, L., 2010. Predictors of learner satisfaction and transfer of learning in a corporate online education program. The American Journal of Distance Education, 24(4), pp.207-226. 
Husserl, E., 1965. Phenomenology and the crisis of philosophy: Philosophy as a rigorous science, and philosophy and the crisis of European man. New York: Harper \& Row.

Johnson, R. B. and Onwuegbuzie, A. J., 2004. Mixed methods research: A research paradigm whose time has come. Educational researcher, 33(7), pp.14-26.

Johnston, T. C., 2015. Lessons from Moocs: Video Lectures and Peer Assessment. Academy of Educational Leadership Journal, 19(2), pp.91-98.

Kizilcec, R. F., 2013. Collaborative learning in geographically distributed and in-person groups. Proceedings of the 2013 AIED Workshops, 67. [online] Available at <http://ceur-ws.org/Vol-1009/aied2013ws_volume1.pdf\#page=72> [Accessed 24 April 2018]

Kizilcec, R. F. and Schneider, E., 2015. Motivation as a lens to understand online learners: Toward data-driven design with the OLEI scale. ACM Transactions on Computer-Human Interaction (TOCHI), 22(2), pp.1-24.

Kulkarni, C., Wei, K. P., Le, H., Chia, D., Papadopoulos, K., Cheng, J., Koller, D. and Klemmer, S. R., 2013. Peer and self assessment in massive online classes. ACM Transactions on Computer-Human Interaction (TOCHI), 20(6), pp.1-31.

Kurucay, M. and Inan, F. A., 2017. Examining the effects of learner-learner interactions on satisfaction and learning in an online undergraduate course. Computers \& Education, 115, pp.20-37.

Lee, Y. and Rofe, J. S., 2016. Paragogy and flipped assessment: experience of designing and running a MOOC on research methods. Open Learning: the Journal of Open, Distance and e-Learning, 31(2), pp.116-129.

Liu, M., Kang, J. and McKelroy, E., 2015. Examining learners' perspective of taking a MOOC: reasons, excitement, and perception of usefulness. Educational Media International, 52(2), pp.129-146.

Lu, R., and Bol L.. 2007. "A Comparison of Anonymous Versus Identifiable E-Peer Review on College Student Writing Performance and the Extent of Critical Feedback." Journal of Interactive Online Learning 6 (2), pp. 100-115.

Luo, H., Robinson, A. C. and Park, J. Y., 2014. Peer Grading in a MOOC: Reliability, Validity, and Perceived Effects. Journal of Asynchronous Learning Networks, 18(2), pp.1-14.

Mackness, J., Mak, S. and Williams, R., 2010. The ideals and reality of participating in a MOOC. In Proceedings of the 7 th international conference on networked learning 2010. University of Lancaster.

Martín, O., González, F., and García, M. A., 2013. Propuesta de evaluación de la calidad de los MOOCs a partir de la Guía Afortic. Campus virtuales, 2(1), pp.124-132.

Martín-Monje, E., Bárcena-Martín, E., and Read, T., 2014. La interacción entre compañeros y el feedback lingüístico en los coma de lenguas extranjeras. Profesorado Revista de currículum y formación del profesorado, 18(1), pp. 167-183.

Meek, S. E., Blakemore, L. and Marks, L., 2017. Is peer review an appropriate form of assessment in a MOOC? Student participation and performance in formative peer review. Assessment \& Evaluation in Higher Education, 42(6), pp.1000-1013.

Merriam, S. B. and Tisdell, E. J., 2015. Qualitative research: A guide to design and implementation. John Wiley \& Sons.

Moore, M. G., 1989. Three types of interaction. American Journal of Distance Education, 3(2), pp.1-7.

Mulder, R. A., Pearce, J. M. and Baik, C., 2014. Peer review in higher education: Student perceptions before and after participation. Active Learning in Higher Education, 15(2), pp.157-171.

Najafi, H., Rolheiser, C., Harrison, L. and Haklev, S., 2015. University of Toronto instructors' experiences with developing MOOCs. The International Review of Research in Open and Distributed Learning, 16(3).

Nelson, M. and Schunn, C., 2009. The nature of feedback: How different types of peer feedback affect writing performance. Instructional Science, 37(4), pp.375-401.

Neubaum, G., Wichmann, A., Eimler, S. C. \& Krämer, N. C., 2014. Investigating incentives for students to provide peer feedback in a semi-open online course: An experimental study. Proceedings at The International Symposium on Open Collaboration, pp. 19. ACM. [online] Available at <https://dl.acm.org/citation.cfm?doid=2641580.2641604> [Accessed 24 April 2018]

Piech, C., Huang, J., Chen, Z., Do, C., Ng, A. and Koller, D., 2013. Tuned models of peer assessment in MOOCs. Proceedings at The 6th International Conference on Educational Data Mining, pp. 2579-2585. Dallas, TX: IEEE. [online] Available at <https://arxiv.org/pdf/1307.2579.pdf> [Accessed 25 April 2018]

Ramírez-Fernández, M., 2015. La valoración de MOOC: Una perspectiva de calidad. RIED: Revista lberoamericana de Educación a Distancia, 18(2), pp.171-195.

Reilly, E. D., Stafford, R. E., Williams, K. M., \& Corliss, S. B., 2014. Evaluating the validity and applicability of automated essay scoring in two massive open online courses. The International Review of Research in Open and Distributed Learning, 15(5).

Richards, J. and Schmidt, R. (2010). Longman Dictionary of Language Teaching and Applied Linguistics. Pearson Education, Cambridge.

Ruegg, R., 2015. The relative effects of peer and teacher feedback on improvement in EFL students' writing ability. Linguistics and Education, 29, pp.73-82.

Sánchez, M., 2016. Assessing the quality of MOOC using ISO/IEC 25010. Learning Objects and Technology (LACLO), Latin American Conference, pp.1-4. IEEE.

Shute, 2008. Focus on formative feedback. Review of educational research, 78(1), pp.153-189.

Spector, J. M., 2014. Remarks on MOOCs and mini-MOOCs. Educational Technology Research and Development, 62(3), pp.385-392.

Suen, H. K., 2014. Peer assessment for massive open online courses (MOOCs). The International Review of Research in Open and Distributed Learning, 15(3), pp-312-327.

Tójar, J. C., 2006. Investigación cualitativa: comprender y actuar. Madrid: La Muralla.

Wang, X., Yang, D., Wen, M., Koedinger, K. and Rosé, C. P., 2015. Investigating How Student's Cognitive Behavior in MOOC Discussion Forums Affect Learning Gains. International Educational Data Mining Society.

Wilding, C. and Whiteford, G., 2005. Phenomenological research: An exploration of conceptual, theoretical and practical issues. OTJR: Occupation, Participation and Health, 25(3), pp.98-104.

Yurdabakan, Í., 2016. The investigation of the prospective teachers' opinions related to peer assessment: A qualitative study. International Journal on New Trends in Education \& their Implications (IJONTE), 7(4), pp.1-12. 
The Electronic Journal of e-Learning Volume 18 Issue 22020

\section{Appendices}

Appendix 1: Survey at the beginning of the course

Interest and motivations to evaluate and interact with classmates

\begin{tabular}{|c|c|c|c|c|}
\hline Category & Subcategory & Statement & Scale & References \\
\hline \multirow[t]{2}{*}{ Interaction } & \multirow[t]{2}{*}{$\begin{array}{l}\text { Peer } \\
\text { discussion }\end{array}$} & $\begin{array}{l}\text { 1 I am willing to participate in } \\
\text { discussion groups with participants } \\
\text { that share my own level of experience } \\
\text { on the course's subject. }\end{array}$ & $\begin{array}{l}\text { * Strongly agree } \\
\text { * Agree } \\
\text { * Disagree } \\
\text { * Strongly disagree }\end{array}$ & \multirow[t]{2}{*}{$\begin{array}{l}\text { Martín-Monje, Bárcena- } \\
\text { Martín, and Read (2014) } \\
\text { Johnston (2015) }\end{array}$} \\
\hline & & $\begin{array}{l}2 \text { I am willing to share my knowledge } \\
\text { or experience with participants who } \\
\text { have less experience on the course's } \\
\text { subject. }\end{array}$ & $\begin{array}{l}\text { * Strongly agree } \\
\text { * Agree } \\
\text { * Disagree } \\
\text { * Strongly disagree }\end{array}$ & \\
\hline \multirow[t]{3}{*}{ Feedback } & & $\begin{array}{l}3 \text { I am willing to dedicate at least one } \\
\text { hour a week to provide thoughtful } \\
\text { commentary (feedback) on the work of } \\
\text { other participants. }\end{array}$ & $\begin{array}{l}\text { * Strongly agree } \\
\text { * Agree } \\
\text { * Disagree } \\
\text { * Strongly disagree }\end{array}$ & \\
\hline & & $\begin{array}{l}4 \text { I think that providing thoughtful } \\
\text { comments (feedback) on the work of } \\
\text { others helps me to improve my } \\
\text { knowledge on the subject. }\end{array}$ & $\begin{array}{l}\text { * Strongly agree } \\
\text { * Agree } \\
\text { * Disagree } \\
\text { * Strongly disagree }\end{array}$ & \\
\hline & & $\begin{array}{l}5 \text { l've evaluated works from other } \\
\text { participants at previous MOOC } \\
\text { courses. }\end{array}$ & $\begin{array}{l}\text { * Yes } \\
\text { * No }\end{array}$ & \\
\hline
\end{tabular}

Appendix 2: Survey at the end of the course

Interest and motivations to evaluate and interact with classmates

\begin{tabular}{|c|c|c|c|}
\hline Category & Questions & Answer choices & References \\
\hline \multirow[t]{5}{*}{ Interaction } & 1 I participated in the discussion forums in: & $\begin{array}{l}\text { All the units } \\
\text { Most units } \\
\text { A few units } \\
\text { None of the units }\end{array}$ & $\begin{array}{l}\text { Martín-Monje, Bárcena- } \\
\text { Martín, and Read (2014) }\end{array}$ \\
\hline & $\begin{array}{l}2 \text { I solved my questions on the course's subject in the } \\
\text { discussion forums. }\end{array}$ & $\begin{array}{l}\text { Strongly agree } \\
\text { Agree } \\
\text { Disagree } \\
\text { Strongly disagree }\end{array}$ & Johnston (2015) \\
\hline & $\begin{array}{l}3 \text { I solved the questions of other participants in the } \\
\text { discussion forums. }\end{array}$ & $\begin{array}{l}\text { Yes } \\
\text { No }\end{array}$ & \\
\hline & $\begin{array}{l}4 \text { I improved my knowledge on the course's subject by } \\
\text { participating in the discussion forums. }\end{array}$ & $\begin{array}{l}\text { Strongly agree } \\
\text { Agree } \\
\text { Disagree } \\
\text { Strongly disagree }\end{array}$ & \\
\hline & $\begin{array}{l}5 \text { Write a brief comment regarding your experience } \\
\text { participating in the discussion forums. }\end{array}$ & Open answer & \\
\hline \multirow[t]{3}{*}{ Feedback } & $\begin{array}{l}6 \text { I watched the video on Methodology in the Opening } \\
\text { section, which explains how to evaluate the work of } \\
\text { other participants. }\end{array}$ & $\begin{array}{l}\text { Yes } \\
\text { No }\end{array}$ & $\begin{array}{l}\text { Daradoumis, Bassi, Xhafa } \\
\text { and Caballé (2013) }\end{array}$ \\
\hline & $\begin{array}{l}7 \text { I provided thoughtful comments (feedback) on the } \\
\text { work of other participants and pointed out whether the } \\
\text { work complied with what was requested. }\end{array}$ & $\begin{array}{l}\text { Yes } \\
\text { No }\end{array}$ & Johnston (2015) \\
\hline & $\begin{array}{l}8 \text { Write a brief comment on your experience receiving } \\
\text { thoughtful comments (feedback) made by other } \\
\text { participants. }\end{array}$ & Open answer & \\
\hline
\end{tabular}


Appendix 3: Interview guide

In how many MOOC courses have you participated? What were your motivations to take the course? Interaction

1. What has been your experience participating in MOOCs' discussion forums?

2. What are your interests in participating in discussion forums? Which role do you prefer to take in the MOOC discussion forums? (observe, write, debate, solve questions, etc.).

3. How do you feel about participating as a novice or expert? Is it easy to identify in the contributions if the participant is an expert or a novice?

4. Would you be interested in interacting personally with other participants with the same interests as yours?

5. What would you improve in the discussion forums to improve interaction?

6 . In what way did you receive feedback in the course? What about the interaction with your colleagues made you feel your received feedback?

Feedback

7. What has been your experience giving and receiving feedback on written work in a MOOC?

8. What is your interest in providing and receiving feedback from your colleagues? What do you expect when receiving feedback?

9. How capable do you consider yourself to give feedback to your classmates' work?

10. Why would you or wouldn't you be willing to give feedback to your colleagues' work, for one hour a week?

11. What benefit did you get from the feedback of your classmates? Do you think that providing feedback on your classmates' work improves your knowledge on the subject of study?

12. Can you tell when an expert participant gives you feedback? Do you think that the benefits of the contributions are any different when they come from an expert?

13. Which characteristics would you prefer in a person with whom you will participate in processes of feedback or collaborative work?

14. Did the quizzes, the questions at the end of the videos, and the multiple-choice question in the challenge help you in your learning? What benefit did you get from those activities?

15. What's the difference between this kind of feedback and the one you can receive from your classmates? 